\title{
Colorimetric method for determination of some 1,4-dihydropyridine drugs in their tablets and capsules
}

Mohamed A. El Hamdª,b ${ }^{\star}$ Sayed M. Derayeac ${ }^{c}$, Osama H. Abdelmageed ${ }^{d}$ and Hassan F. Askal ${ }^{\mathrm{e}}$

aDepartment of Pharmaceutical Analytical Chemistry, Faculty of Pharmacy, Al-Azhar University, Assiut 71524, Egypt

${ }^{b}$ Graduate School of Biomedical Sciences, Course of Pharmaceutical Sciences, Nagasaki University, Nagasaki 852-8521, Japan

Abo elhamd2007@yahoo.com

${ }^{\mathrm{C} D}$ Department of Pharmaceutical Analytical Chemistry, Faculty of Pharmacy, Minia University, Minia 61519, Egypt

dDepartment of Pharmaceutical Chemistry, Faculty of Pharmacy, King Abdulaziz University, Jeddah 21589, Kingdom of Saudia Arabia

eDepartment of Pharmaceutical Analytical Chemistry, Faculty of Pharmacy, Assiut University, Assiut 71526, Egypt

\section{ABSTRACT}

A simple, accurate and selective colorimetric method was developed and validated for determination of five of 1,4dihydropyridine drugs (1,4-DHP) using tetrabutylammonium hydroxide reagent (TBAH). The proposed method was based on addition of TBAH to the studied drugs then the produced yellow colors were measured spectrophotometrically. Different variables which affecting the reaction conditions were carefully studied and optimized. Under the optimum conditions, Beer's law was obeyed in the concentration range of $2.50-40.0 \mu \mathrm{g} / \mathrm{mL}$ and the limits of detection were ranged from $0.750-$ $1.956 \mu \mathrm{g} / \mathrm{mL}$. The proposed method was successfully extended to the pharmaceutical preparations, tablets and capsules. The obtained results were comparable with that obtained by the reference methods.

Keywords: Colorimetric method; five 1,4-DHP drugs; TBAH

\section{Council for Innovative Research}

Peer Review Research Publishing System

Journal: Journal of Advances in Chemistry

Vol 4, No.1

editor@cirworld.com

www.cirworld.com, member.cirworld.com 


\section{INTRODUCTION}

Hypertension or high blood pressure is a cardiac chronic condition in which the systemic arterial blood pressure is elevated. It is classified either a primary (essential) hypertension or secondary hypertension. About $90-95 \%$ of cases are categorized as primary hypertensive and the remaining $5-10 \%$ of cases are secondary hypertensive patients. Although the dietary and lifestyle changes can improve the blood pressure and decrease the risk of associated health complications, but drug treatment may be necessary in patient for whom lifestyle changes are ineffective or insufficient.

Calcium ions play an important role in function of cardiovascular system and the calcium channel blockers (CCB) primarily exert their activities through inhibiting the calcium ion entry into the cells. Also CCB affect the cardiac and vascular smooth muscle cells and cause vasodilatation for both coronary and peripheral arteries, hence reducing the blood pressure [1, 2]. Nifedipine (NIF), nicardipine (NIC), nimodipine (NIM), felodipine (FEL) and amlodipine (AML), Figure 1 are the prototypical 1,4-DHP derivatives and they are considered as CCB agents. Furthermore, they are useful in other pathological states, such as seizures and central ischemic disorders [3].<smiles>CCOC(=O)C1=C(C)NC(C)=C(C(=O)OC)C1c1cccc(Cl)c1Cl</smiles>

Detailed survey of literatures for NIF revealed that several UV-Visible spectrophotometry methods that have been reported for its assay either alone or in combination with other drugs [4-13]. But only a few spectrophotometric and spectrofluorimetric methods have been reported for determination of NIC [10, 11,13-17]. NIM has another advantage than other its members, it is recommended for improvement of neurological outcomes by reducing the incidence and severity of ischemic deficits in patients with subarachnoid hemorrhage $[18,19]$; for its assay a different spectrophotometric methods have been described in the present literatures [10,11, 19-25]. In the quantitative determination of FEL in pharmaceutical dosage forms, spectrometric methods have been published [10, 11,26-29]. Also AML has been assayed in its pure and pharmaceutical dosage forms using different spectrometric methods [10, 11, 16, 30-51].

The main goal of this work is to establish a simple, accurate, precise, and reproducible spectrophotometric method for determination of these drugs in bulk and in their pharmaceutical preparations. Further, the established method should be rapid and economic to be applied for the routine quality control analysis or in pharmaceutical dosage forms.

\section{EXPERIMENTAL}

\section{Instrumentation:}

Absorbance measurements were made on Shimadzu-1601UV-Visible Spectrophotometer (Shimadzu, Tokyo, Japan), Jenway-6305 UV-Visible Spectrophotometer (Jenway LTD, U.K).

\section{Reagents and solutions:}

A $25 \mathrm{mg} / \mathrm{mL}$ of TBAH (Sigma Chemical Co., St. Louis, USA) solution was prepared in dimethylsulphoxide (DMSO) (Laba Chemie, Mumbai, India). Reference standards of pure drugs (NIF, NIC, NIM, FEL, AML and other combined drugs such as atenolol and metoprolol) were generously supplied from their respective manufacturers. $0.5 \mathrm{mg} / \mathrm{mL}$ of stock standard were prepared in DMSO; the working standard solutions were prepared by further dilution with DMSO.

\section{Procedure for calibration curves:}

An aliquot of $1.0 \mathrm{~mL}$ of the standard or sample solution was transferred into $10 \mathrm{~mL}$ calibrated flask. $1.0 \mathrm{~mL}$ of TBAH was added; the reaction was allowed to proceed for $20 \mathrm{~min}$ then diluted to the mark with DMSO. The absorbance of the resulting yellow color solutions were measured at 432, 447, 458, 457 and $464 \mathrm{~nm}$ for NIF, NIC, NIM, FEL, and AML respectively, versus experimental blank treated similarly. 


\section{Pretreatment procedure for the assay of tablets and capsules:}

The contents of twenty tablets or capsules were mixed thoroughly and quantities of the powder equivalent to $50 \mathrm{mg}$ of the active ingredient were dissolved in $50 \mathrm{~mL}$ DMSO. The contents were swirled and sonicated for 5 min then the mixture was filtered. The collected filtrate was transferred into $100 \mathrm{~mL}$ calibrated flask and completed to the mark with DMSO.

\section{Pretreatment procedure for the assay of tablet and capsule containing two drugs:}

Twenty tablets (Logimax ${ }^{\circledR}$ tablets, FEL and metoprolol) or capsules (Tenolat SR ${ }^{\circledR}$ capsules, NIF and atenolol) were weighted accurately and the contents were mixed thoroughly. Quantities of the powder equivalent to $50 \mathrm{mg}$ of the active ingredient of NIF and FEL were dissolved in $50 \mathrm{~mL}$ DMSO then the procedure was completed as the previous.

\section{RESULTS AND DISCUSSION}

The proposed method was focused on treatment of 1,4-DHP drugs with TBAH base in DMSO. Figure 2 (AML, as a representative example) illustrates the bathochromic shift of the colored chromogen from the original spectrum of $A M L$. Through the literatures; the corresponding anions of dihydropyridine are prepared by reaction of Hantzsch type dihydropyridines moiety with a strong base in a non-polar solvent, but unfortunately, nothing is known about the site of protonation, i.e. those have electron withdrawing substituents in both 3 and 5 positions [52, 53]. Exploratory experiments for such compound showed that the nature of the protonated species depended upon both the solvent and the base strength [54]. J. Luis et al. [55] explained the addition of TBAH base to 1,4-DHP drugs in DMSO produces a drastic bathochromic shift that is due to anion formation in the basic medium utilizing the proton in 1,4-DHP ring and the band gradually disappeared after addition of perchloric acid solution. Subsequently, as Figure 3 shows, we verified this suggested neutralization reaction after color formation.

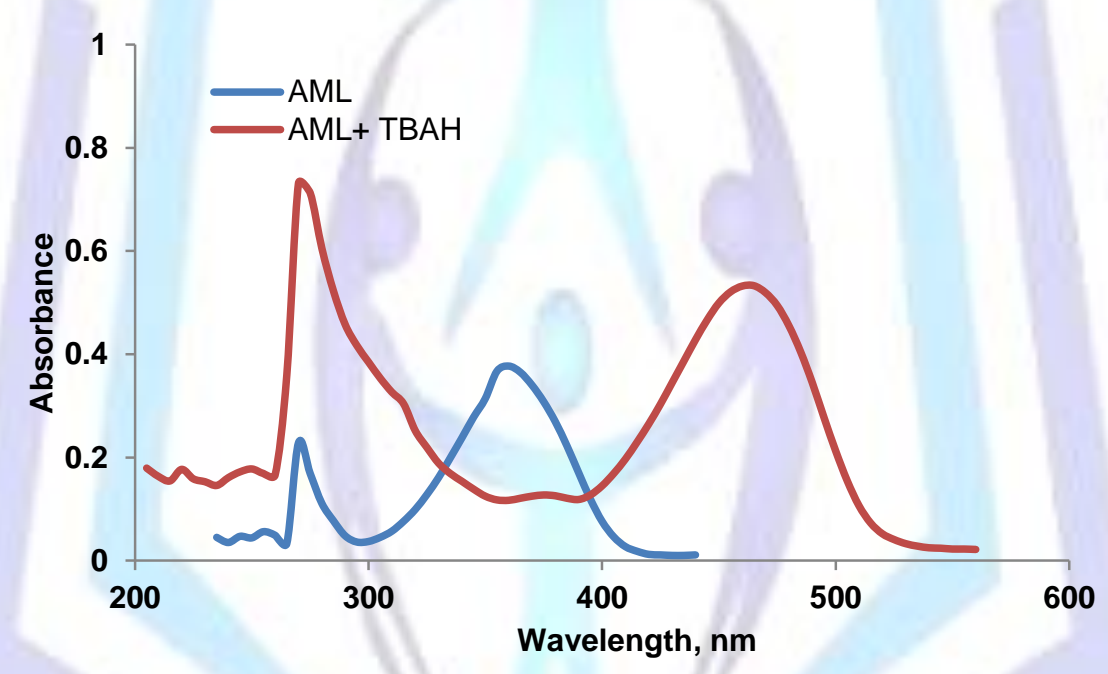

Fig 2. Absorption spectra of AML, $20 \mu \mathrm{g} / \mathrm{mL}$ and its colored product after addition of TBAH

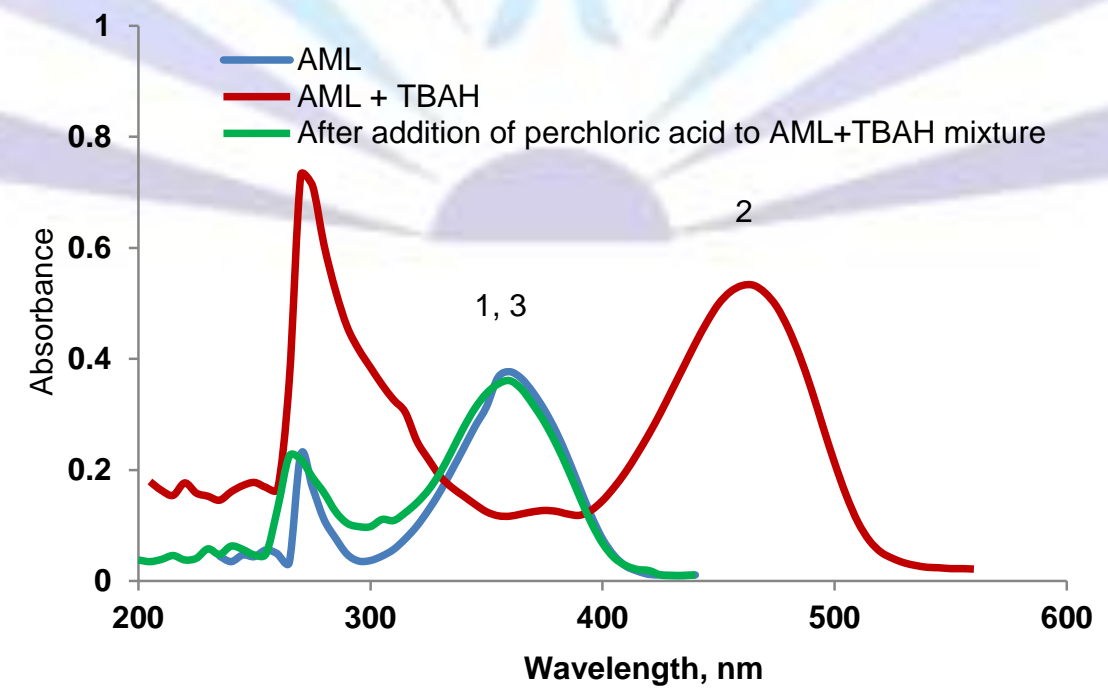

Fig 3. Absorption spectra of (1) AML, $20 \mu \mathrm{g} / \mathrm{mL}$ (2) AML after addition of TBAH (3) AML and TBAH reaction product after addition of $0.1 \mathrm{M}$ perchloric acid, $1.0 \mathrm{~mL}$ 


\section{OPTIMIZATION OF PARAMETERS:}

Different variables such as type and concentration of the alkali, reaction time, temperature, and the diluting solvent, which influencing the intensity of the colored products were studied and optimized.

\section{Basic reagent and organic solvents system:}

Preliminary experiments were carried out to select the type of alkali and the organic medium; the results that were obtained revealed that the highest reaction products chromogen achieved when TBAH used compare to other used alkali such as $\mathrm{NaOH}, \mathrm{KOH}$ and tetraethylammonum hydroxide solution. The greatest colors were obtained in dipolar aprotic solvents such as acetone, dimethyl formamide (DMF) or DMSO and the formed colors intensity increased relatively by increasing in dielectric constant of these solvents (20.7, 36.71 and 46.68 for acetone, DMF and DMSO, respectively [56]). Water and other protic solvent such as ethanol, methanol and propanol have a destructive effect on the formed chromogen. Therefore the highest and the stable absorption intensity for the produced colored products were observed when TBAH/DMSO system was used.

\section{TBAH concentration:}

$25 \mathrm{mg} / \mathrm{mL}$ TBAH regent was selected from different studied concentrations ranged from 10-45 mg/mL of TBAH, Figure 4.

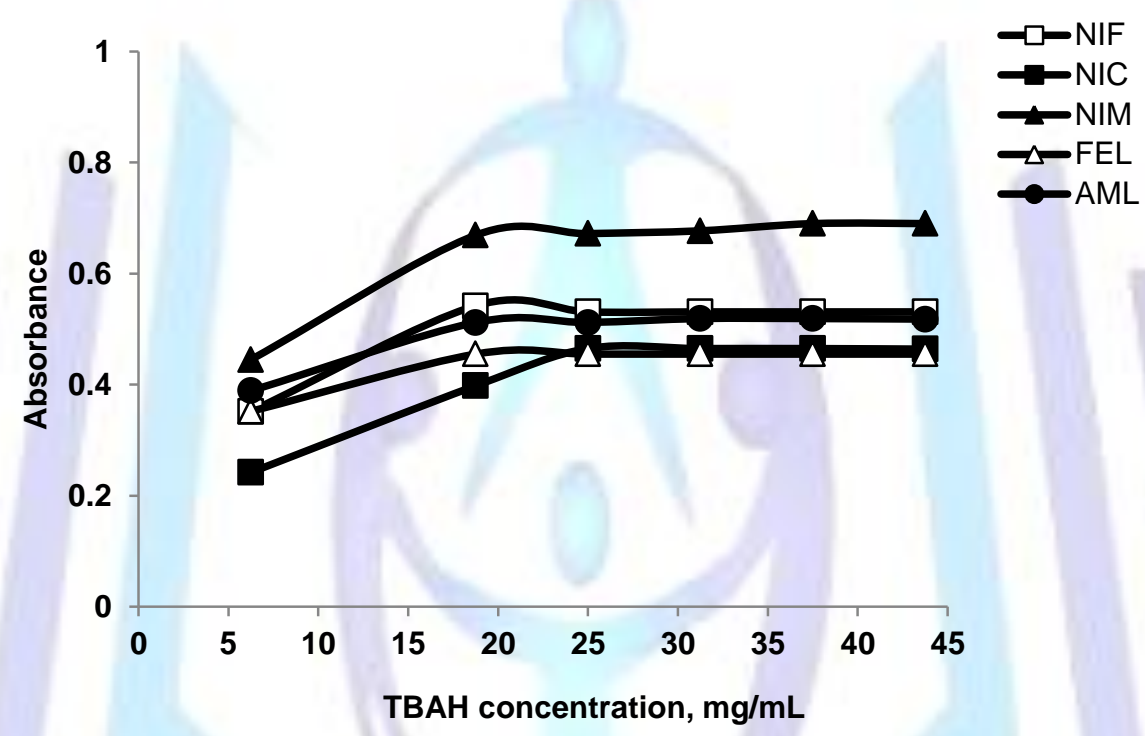

Fig 4. Effect of TBAH concentration on the absorption intensity of the reaction products with $1,4-\mathrm{DHPs}, 20 \mu \mathrm{g} / \mathrm{mL}$

\section{Reaction time:}

The reaction between drugs and TBAH was completed after $20 \mathrm{~min}$ at room temperature $\left(25 \pm 5^{\circ} \mathrm{C}\right)$ and the absorbance values of the colored products remained stable for more than $30 \mathrm{~min}$ after their dilution, Figure 5.
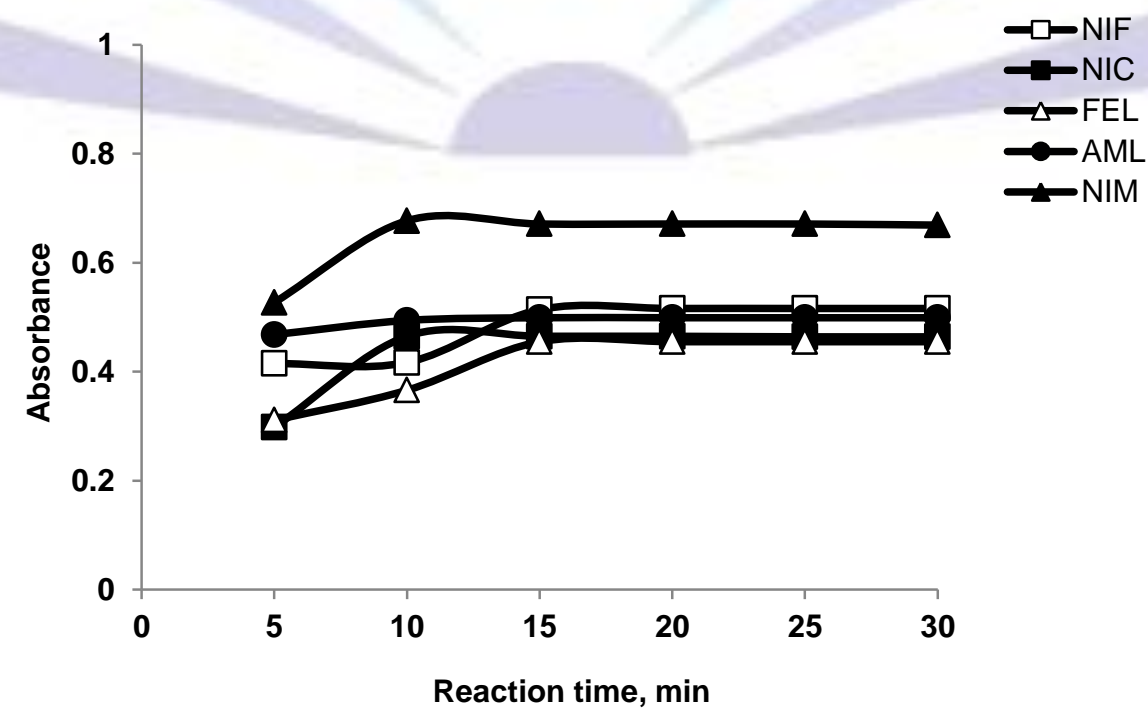

Fig 5.Time effect on the color intensity of the reaction products of TBAH with 1,4-DHP, $20 \mu \mathrm{g} / \mathrm{mL}$ 


\section{REACTION STOICHIOMETRY}

Job's method of continuous variation [57] was employed to establish the stoichiometry of proposed method. The ratios between the investigated drugs and TBAH were 1:2; Figure 6 using NIF as representative example.

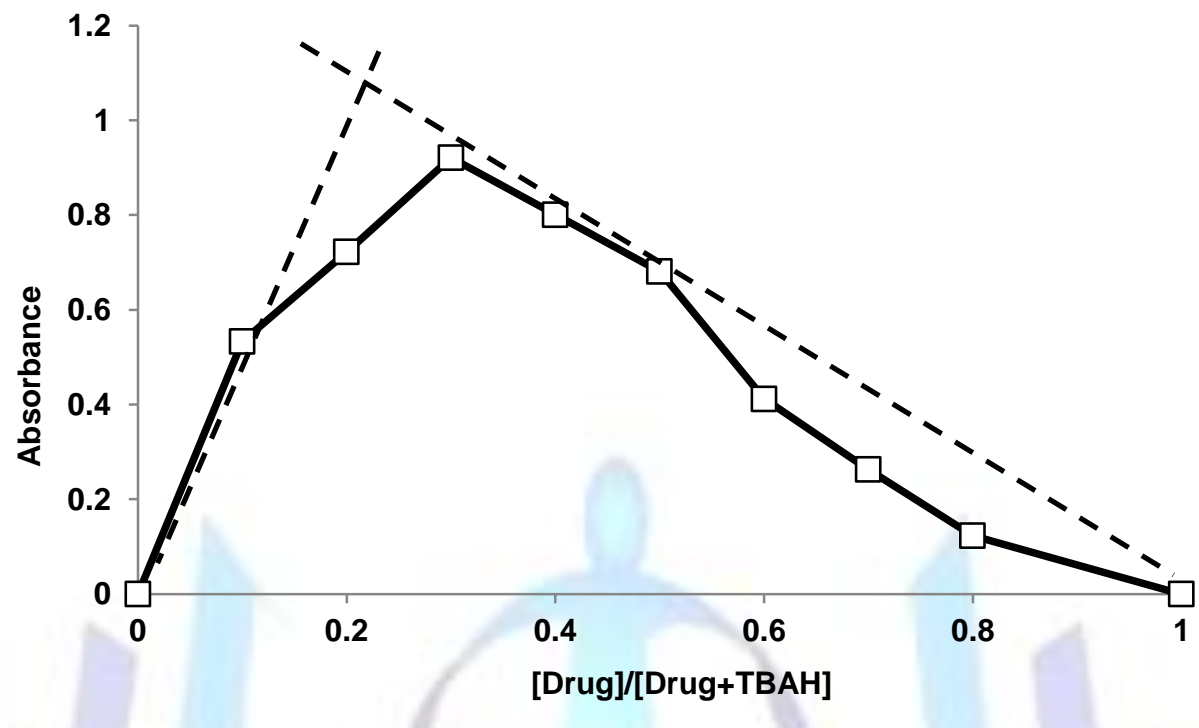

Fig 6. Job's plot for the reaction TBAH with NIF

\section{Suggested reaction between the studied drugs and NBS:}

Based on previous literatures, our experimental finding and the calculated molar ratios we suggested that the reaction mechanism is anion formation between acidic $\mathrm{N}-\mathrm{H}$ and TBAH, as illustrated in Scheme 1. The aromatization of the 1,4DHP ring is difficult under this conditions; that was established by the destructive effect of perchloric acid on the developed chromogen. The new finding in this study is the negative effect of nitro group on the reaction pass-way as it was reported in the previous explanations $[6,32,58]$.<smiles>[R]C1=C(C)NC(C)=C([R])C1[R2]</smiles><smiles>[PbH2]</smiles><smiles>[R]c1c([R])c(C)[n+]([O-])c(C)c1[R2]</smiles>

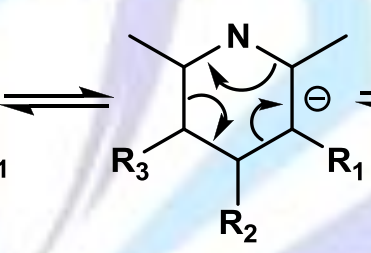<smiles>C=C</smiles>

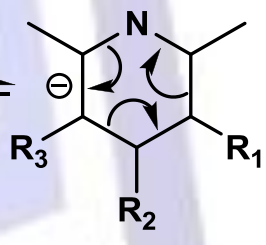

\section{1,4-DHP derivatives}

Scheme 1. The suggested reaction pathway of reaction between 1,4-DHP and TBAH

\section{VALIDATION OF PROPOSED METHODS}

The developed procedures were fully validated according to USP XXVI [59] validation guidelines and International Conference on Harmonization (ICH) guidelines [60].

\section{Linearity range, detection and quantification limits:}

Calibration curves for the investigated drugs with TBAH method constructed by analyzing a series of different concentrations of the drug standard solutions. Linear relationships were found between the measured values of the absorbance intensities and the concentrations of the investigated drugs as indicated by the high correlation coefficients obtained $(r)$, in the concentrations were ranged from $2.50-40.0 \mu \mathrm{g} / \mathrm{mL}$. The limit of detection (LOD) and limit of quantitation (LOQ) were determined according to the IUPAC definitions [61] using the formula LOD or LOQ $=\kappa S D_{a / b}$; where $\kappa=3$ for $\mathrm{LOD}$ and 10 for $\mathrm{LOQ}, \mathrm{SD}_{\mathrm{a}}$ is the standard deviation of the intercept and $\mathrm{b}$ is the slope. The regression equations for the results derived using the least square method and the obtained results summarized in Table 1. 
Table 1. Quantitative parameters and statistical data for the proposed method

\begin{tabular}{lcccccc}
\hline Drug & $\begin{array}{c}\text { Linear range } \\
\mu \mathrm{g} / \mathrm{mL}\end{array}$ & $r$ & Regression equation & $\begin{array}{c}\mathrm{LOD} \\
\mathrm{Mg} / \mathrm{mL}\end{array}$ & $\begin{array}{c}\mathrm{LOQ} \\
\mu \mathrm{g} / \mathrm{mL}\end{array}$ & $\begin{array}{c}\varepsilon^{*} \times 10^{4} \\
\mathrm{l} / \mathrm{mol} / \mathrm{m}\end{array}$ \\
\hline $\mathrm{NIF}$ & $2.5-35$ & 0.996 & $\mathrm{y}=0.023 \mathrm{x}+0.015$ & 1.956 & 6.521 & 0.893 \\
$\mathrm{NIC}$ & $2.5-35$ & 0.996 & $\mathrm{y}=0.021 \mathrm{x}+0.010$ & 0.750 & 2.500 & 1.137 \\
$\mathrm{NIM}$ & $5.0-40$ & 0.999 & $\mathrm{y}=0.021 \mathrm{x}+0.009$ & 1.280 & 4.285 & 0.939 \\
$\mathrm{FEL}$ & $2.5-30$ & 0.997 & $\mathrm{y}=0.031 \mathrm{x}+0.014$ & 1.354 & 4.516 & 1.370 \\
AML & $2.5-35$ & 0.996 & $\mathrm{y}=0.024 \mathrm{x}+0.010$ & 1.125 & 3.751 & 1.460 \\
\hline
\end{tabular}

${ }^{1} \mathrm{y}$ : absorbance and $\mathrm{x}$ : Sample conc., $\mu \mathrm{g} / \mathrm{mL}$

${ }^{\star} \varepsilon$ : The molar absorptivity

\section{Precision and accuracy:}

The proposed method's precision was determined by carrying out replicate analysis of five separated solutions of the working standards at one concentration level. The relative standard deviations (RSD) of the results did not exceed $2 \%$, for intra- and inter-day precision indicating a good repeatability and reproducibility with acceptable accuracy of the proposed method. Table 2

Table 2. Assay of five replicate samples of the studied drugs by TBAH at one concentration level

\begin{tabular}{lcccc}
\hline & & \multicolumn{2}{c}{$\begin{array}{c}\text { Precision RSD (\%) } \\
(\mathrm{n}=5)\end{array}$} \\
\cline { 4 - 5 } Drug & Conc., $\mu \mathrm{g} / \mathrm{mL}$ & $\begin{array}{c}\text { Accuracy } \% \\
(\mathrm{n}-5)\end{array}$ & Intra-day & Inter-day \\
\hline NIF & 20 & $91.1 \pm 0.004$ & 0.38 & 1.6 \\
NIC & 25 & $96.4 \pm 0.003$ & 0.73 & 1.8 \\
NIM & 15 & $100.0 \pm 0.004$ & 0.63 & 1.2 \\
FEL & 20 & $95.1 \pm 0.003$ & 0.53 & 1.4 \\
AML & 20 & $101.4 \pm 0.003$ & 0.39 & 1.5 \\
\hline
\end{tabular}

\section{Robustness and Ruggedness}

The proposed method's robustness was examined by evaluating the influence of small variation in some experimental parameters on its suitability and specificity. The changed parameters were the concentration of TBAH and the reaction time. It was found that none of these variables significantly affect the original data of the proposed method, Table 3.

Table 3. Robustness of the proposed method

\begin{tabular}{|c|c|c|c|c|c|}
\hline \multirow[b]{2}{*}{ Variation } & \multicolumn{5}{|c|}{ Recovery $\% \pm$ SD $^{a}$} \\
\hline & $\mathrm{NIF}^{\mathrm{b}}$ & $\mathrm{NIC}^{\mathrm{b}}$ & $\mathrm{NIM}^{\mathrm{b}}$ & $\mathrm{FEL}^{\mathrm{b}}$ & $\mathrm{AML}^{\mathrm{b}}$ \\
\hline No variation & $98.34 \pm 0.23$ & $97.21 \pm 0.24$ & $98.38 \pm 0.25$ & $99.30 \pm 1.25$ & $99.22 \pm 0.26$ \\
\hline \multicolumn{6}{|l|}{ TBAH conc. } \\
\hline $24.75 \mathrm{mg} / \mathrm{mL}$ & $99.40 \pm 1.23$ & $98.20 \pm 1.12$ & $97.27 \pm 1.28$ & $99.52 \pm 1.20$ & $99.20 \pm 0.26$ \\
\hline $25.25 \mathrm{mg} / \mathrm{mL}$ & $98.24 \pm 1.22$ & $98.11 \pm 0.34$ & $98.19 \pm 0.47$ & $99.23 \pm 1.14$ & $99.51 \pm 1.18$ \\
\hline \multicolumn{6}{|l|}{ Reaction time } \\
\hline $19 \min$ & $98.27 \pm 1.34$ & $98.20 \pm 0.21$ & $99.37 \pm 0.81$ & $99.31 \pm 0.77$ & $99.65 \pm 1.36$ \\
\hline $21 \mathrm{~min}$ & $99.25 \pm 1.22$ & $98.43 \pm 0.13$ & $98.27 \pm 0.87$ & $99.34 \pm 0.36$ & $99.89 \pm 0.56$ \\
\hline
\end{tabular}


The proposed method's ruggedness was tested by applying the assay of the investigated drugs using the same conditions but using two different instruments at two different laboratories and different elapsed time, the results obtained were found to be reproducible as RSD did not exceed $2 \%$, Table 4.

Table 4. Ruggedness of the proposed TBAH method

\begin{tabular}{|c|c|c|c|c|c|}
\hline \multirow{3}{*}{ Drugs $^{b}$} & \multicolumn{5}{|c|}{ Recovery $\% \pm S^{S D^{a}}$} \\
\hline & \multicolumn{2}{|c|}{ Instrument } & \multicolumn{3}{|c|}{ Inter-day variation } \\
\hline & Shimadzu & Jenway & Day-1 & Day-2 & Day-3 \\
\hline NIF & $99.24 \pm 0.89$ & $99.21 \pm 1.24$ & $98.32 \pm 0.23$ & $97.22 \pm 1.56$ & $99.62 \pm 0.51$ \\
\hline NIC & $99.66 \pm 1.17$ & $99.99 \pm 1.18$ & $97.27 \pm 0.24$ & $99.08 \pm 1.35$ & $98.81 \pm 0.44$ \\
\hline NIM & $99.92 \pm 1.27$ & $99.10 \pm 0.66$ & $98.30 \pm 0.13$ & $99.24 \pm 1.33$ & $98.40 \pm 0.69$ \\
\hline FEL & $98.17 \pm 1.22$ & $99.11 \pm 0.18$ & $99.13 \pm 1.25$ & $98.51 \pm 0.56$ & $98.49 \pm 1.56$ \\
\hline AML & $99.29 \pm 1.83$ & $98.15 \pm 1.88$ & $99.02 \pm 0.26$ & $97.29 \pm 1.34$ & $98.41 \pm 1.34$ \\
\hline
\end{tabular}

The selectivity of the method was checked by monitoring a standard solutions of the drugs in the presence of other ingredients which present in the tablets and capsules, such as atenolol or metoprolol with NIF and FEL, respectively or excipients [62], the response was not different from that obtained in the calibration curves.

\section{Application of the proposed method}

Tablets and capsules were subjected to analysis for their contents from 1,4-DHP drugs using the proposed method, Table 5. The results were compared with those obtained from either official [63] or reported methods [14, 40], with respect to the accuracy (t-test) and precision (F-test). No significant differences were found between the calculated and theoretical values of $\mathrm{t}-$ and $\mathrm{F}$-tests at $95 \%$ confidence level proving similar accuracy and precision in the analysis of the investigated drugs in their dosage forms.

Table 5. Determination of the studied drugs in their tablets and capsules using TBAH and official or reported methods

\begin{tabular}{|c|c|c|c|c|}
\hline Product & & & & \\
\hline & Proposed method & Official or reported method ${ }^{\mathrm{C}}$ & F-value ${ }^{b}$ & $t$-value \\
\hline Epilate $^{(\otimes)}$ capsules & $97.43 \pm 0.12$ & $99.52 \pm 0.11$ & 2.98 & 1.67 \\
\hline Epilate Retard ${ }^{(\Theta)}$ tablets & $99.45 \pm 0.17$ & $98.51 \pm 0.13$ & 2.13 & 1.20 \\
\hline Tenolat SR ${ }^{\oplus}$ capsules ${ }^{*}$ & $97.21 \pm 0.12$ & $100.52 \pm 0.66$ & 1.81 & 1.61 \\
\hline (Pelcard SR $^{(\circledast)}$ capsules $)^{C}$ & $98.56 \pm 0.02$ & $99.74 \pm 0.11$ & 1.62 & 2.24 \\
\hline Nimotop ${ }^{(\theta)}$ tablets & $99.48 \pm 0.15$ & $98.61 \pm 0.19$ & 1.49 & 1.93 \\
\hline Plendil ${ }^{(\mathbb{B})}$ tablets & $97.69 \pm 0.10$ & $99.24 \pm 0.13$ & 2.64 & 1.67 \\
\hline Plentopine ${ }^{(\Theta)}$ tablets & $97.52 \pm 0.15$ & $99.22 \pm 0.11$ & 1.62 & 1.18 \\
\hline Logimax $^{(\Theta)}$ tablets* $^{*}$ & $99.31 \pm 0.18$ & $99.34 \pm 0.17$ & 1.12 & 0.36 \\
\hline (Alkapress $^{(\Theta}$ tablets) ${ }^{\mathrm{C}}$ & $98.40 \pm 0.19$ & $99.21 \pm 0.12$ & 4.69 & 1.80 \\
\hline (Myodura $^{(\Theta}$ tablets) $)^{\mathrm{C}}$ & $98.24 \pm 0.13$ & $98.31 \pm 0.11$ & 1.39 & 0.16 \\
\hline (Amlodipine $^{(\circledast)}$ tablets $)^{C}$ & $99.23 \pm 0.11$ & $97.20 \pm 0.12$ & 1.00 & 1.23 \\
\hline$\left(\right.$ Regcor $^{(\theta)}$ tablets $^{\mathrm{C}}$ & $99.39 \pm 0.12$ & $99.24 \pm 0.16$ & 1.14 & 0.20 \\
\hline$\left(\text { Vasonorm }^{(\otimes)} \text { tablets }\right)^{\mathrm{C}}$ & $98.33 \pm 0.16$ & $98.41 \pm 0.19$ & 1.14 & 0.17 \\
\hline
\end{tabular}




\section{CONCLUSION}

A yellow color that formed under the above mentioned conditions measured spectrophotometrically can be regarded as anion formation between acidic N-H in 1,4-DHP drugs and TBAH alkali. The new finding in this study is the negative effect of nitro group on the reaction pass-way as it reported in the previous explanations. The proposed method have the advantages of simplicity, sensitivity, selectivity and reproducibility, which satisfies the need for a rapid procedure for routine determination of 1,4-DHP drugs in bulk or in their dosage forms.

\section{ACKNOWLEDGEMENT}

I would like to express my sincere appreciation and everlasting thanks to my supervisor prof. dr. Hassan Farghaly Askal, professor of pharmaceutical analytical chemistry and vice dean of faculty of pharmacy, Assuit university, for suggesting this point of research and continuous supervision, helpful criticism, fruitful discussion and encouragement.

\section{REFERENCES}

[1] N. Kalra, S. Choudhary, Development of spectrophotometric methods for the estimation of water insoluble calcium channel blockers using hydrotropic solubilization technique. World J. Pharma. Res. 1, 1361 (2012).

[2] S. Sweetman, Martindale: The Complete Drug Reference, The Pharmaceutical Press. (London, 2009).

[3] Y. Ikegaya, N. Nishiyama, N. Matsuki, L-type $\mathrm{Ca}^{2+}$ channel blocker inhibits mossy fiber sprouting and cognitive deficits following pilocarpine seizures in immature mice. Neuroscience 98, 647 (2000).

[4] S.P. Vyas, S. K. Goswami, H. G. Vishwavidyalaya, A sensitive visible-spectrophotometric method for the estimation of nifedipine. Indian Drugs 30, 342 (1993).

[5] AFM. EI-Walily, Analysis of nifedipine-acebutolol hydrochloride binary combination in tablets using UV-derivative spectroscopy, capillary gas chromatography and high-performance liquid chromatography. J. Pharm. Biomed. Anal. 16, 21 (1997).

[6] N. Rahman, S. N. H. Azmi, New spectrophotometric methods for the determination of nifedipine in pharmaceutical formulations. Acta Bioch. Polonica. 52, 915 (2005).

[7] N. Rahman, N. A. Khan, S. N. H. Azmi, Extractive spectrophotometric methods for the determination of nifedipine in pharmaceutical formulations using bromocresol green, bromophenol blue, bromothymol blue and eriochrome black T. II Farmaco 59, 47 (2004).

[8] N. N. Rahman, M. Hoda-Nasrul, Spectrophotometric method for the determination of nifedipine with 4(methylamino) phenol and potassium dichromate. II Farmaco 57, 435 (2002).

[9] N. Rahman, S. N. H. Azmi, Method for determination of nifedipine in pure form and in pharmaceutical preparations. Acta Pharm. 49113 (1999).

[10] H. F. Askal, O. H. Abdelmageed, S. M.S. Ali, M. A. E. Hamd, Spectrophotometric and spectrofluorimetric determination of 1,4-dihydropyridine drugs using potassium permanganate and cerium (iv) ammonium sulphate. Bull. Pharm. Sci., Assiut University 33, 201 (2010).

[11] M. A. El Hamd, S. M. Derayea, O. H. Abdelmageed, H. F. Askal, A novel spectrophotometric method for determination of five 1,4-dihydropyridine drugs in their tablets and capsules using vanillin reagent. Ame. J. Anal. Chem. 4, 148 (2013).

[12] S. A. Aderibigbe, O. A. Adegoke, O. S. Idowu, A new colorimetric method for the determination of nifedipine tablets by derivatization using 4-carboxyl-2,6-dinitrobenzene diazonium ion. Inter. J. Indust. Chem. 3, 5 (2012).

[13] Sh. M. Al-Ghannam, A. M. Al-Olyan, Spectrofluorometric determination of nicardipine, nifedipine and isradipine in pharmaceutical preparations and biological fluids. Cent. Eur. J. Chem.6, 222 (2008).

[14] H. Huang, H. Li, Ultra-Violet spectrophotometric determination of the content of nicardipine preparations. Yaowu Fenxi Zazhi 10, 359 (1990).

[15] G. Ragno, C. Vetuschi, UV derivative spectrophotometric assay of nicardipine and its photo degradation product. Pharmazie 53, 628 (1998).

[16] S. M. Derayea, H. F. Askal, O. H. Abdelmageed, M. A. El Hamd, Spectrophotometric determination of amlodipine and nicardipine in pharmaceutical formulations via binary complex formation with eosin Y. J. Appli. Pharm. Sci. 2, 84 (2012).

[17] Sh. M. Al-Ghannam, A. M. Al-Olyan, Spectrophotometric determination of nicardipine and Iseradepine in pharmaceutical formulations. Chem. Indus. and Chem. Engin. Quart. 15 69-76 (2009).

[18] H. Nguyen, Bioequivalence reviews: ANDA 76. In division of bioequivalence review. U.S Food and drug ddministration, (2004). 
[19] M. K. Riekes, G. S. Rauber, G. Kuminek, M. P. Tagliari, S. G. Cardoso, H. K. Stulzer, Determination of nimodipine in the presence of its degradation products and overall kinetics through a stability indicating LC method. J. Chromat. Sci.1, 6 (2012).

[20] S. N. Bharathi, M. S. Prakash, M. Nagarajan, K. A. Kumar, Spectrophotometric determination of nimodipine and its formulations. Indian Drugs36, 661 (1999).

[21] M. Liu, Ultra-violet spectrophotometric determination of nimodipine in tablets. Yaowu Fenxi Zazhi10, 171 (1990).

[22] M. N. Reddy, T. K. Murthy, K. V. Rao-Kanna, A. V. Gopal-Hara, D. G. Sankar, New spectrophotometric method for determination of nimodipine. Indian Drugs 38, 140 (2001).

[23] J. A. Squella, J. C. Sturm, R. Lenac, L. J. Nunez-Vergara, Polarographic and spectrophotometric determination of nimodipine in tablets. Anal. Lett. 25, 281 (1992).

[24] H. D. Revanasiddappa, H. N. Deepakumari, S. M. Mallegowda, K. B. Vinay, Facile spectrophotometric determination of nimodipine and nitrazepam in pharmaceutical preparations. Analele Universt. din Bucuredti 20, 189 (2011).

[25] Y. J. Zhao, H. Y. Lang, Cerium(IV) oxidation-spectrometry for determination of nimodipine. Fenxi Shiyanshi23, 44 (2004).

[26] B. Kanakapura, C. Umakanthappa, N. Paregowda, Titrimetric and spectrophotometric assay of felodipine in tablets using bromate-bromide, methyl orange and indigo carmine reagents. J. Serb. Chem. Soc. 70, 969 (2005).

[27] S. N. Meyyanathan, O. Pradeep, S. Ravi-Sankar, B. Suresh, Simple spectrophotometric analysis of felodipine. Indian Drugs 32, 55 (1995).

[28] F. A. El Yazbi, M. E. Mahrous, H. H. Hammud, Gh. M. Sonji, N. M. Sonji, Comparative spectrophotometric, spectrofluorometric, and high performance liquid chromatographic study for the quantitative determination of the binary mixture of felodipine and ramipril in pharmaceutical formulations. Anal. Lett. 41, 853 (2008).

[29] U. S. Mote, S. L. Bhattar, S. R. Patil, G. B. Kolekar, Interaction of fluorescein with felodipine: a spectrofluorometric and thermodynamic study. J. Solu. Chem. 38, 619 (2009).

[30] K. Sridhar, C. S. P. Sastry, M. N. Reddy, D. G. Sankar, K. Rama-Srinivas, Spectrophotometric determination of amlodipine besylate in pure forms and tablets. Anal. Lett. 30,121 (1997).

[31] S. Singh, R. Jain, Simultaneous spectrophotometric determination of atenolol and amlodipine besylate from dosage forms. Indian Drugs 34, 678 (1997).

[32] S. N. Meyyanathan, J. Joel, S. Scaria, S. Sowmya, B. Suresh, Simple spectrophotometric analysis of amlodipine besylate. Indian Drugs 35, 296 (1998).

[33] H. K. Jain, R. K. Agrawal, Spectrophotometric methods for simultaneous estimation of amlodipine besylate and lisinopril in tablets. Indian Drugs 37, 196 (2000).

[34] N. Rahman, S. N. H. Azmi, Spectrophotometric determination of amlodipine besylate by charge-transfer complex formation with p-chloranilic acid. Anal. Scien.16, 1353 (2000)

[35] S. A. Khopade, N. K. Jain, Difference spectrophotometric estimation of amlodipine besylate. Indian Drugs37, 351 (2000).

[36] N. Rahman, S. N. H. Azmi, Spectrophotometric method for the determination of amlodipine besylate with ninhydrin in drug formulations. II Farmaco 56, 731 (2001).

[37] A. H. Prabhakar, R. Giridhar, A spectrophotometric method for the determination of amlodipine besylate in pure form and in tablets. Indian Drugs 39, 204 (2002).

[38] A. S. Dhake, V. S. Kasture, M. R. Syed, Spectrophotometric method for simultaneous estimation of amlodipine besylate and enalapril maleate in tablets. Indian Drugs 39, 14 (2002).

[39] G. Ragno, A. Garofalo, C. Vetuschi, Photodegradation monitoring of amlodipine by derivative spectrophotometry. J. Pharm. Biomed. Anal. 27, 19 (2002).

[40] B. Kanakapura, U. Chandrashekar, C. Prameela, Sensitive spectrophotometric determination of amlodipine and felodipine using iron (III) and ferricyanide. II Farmaco 58, 141 (2003).

[41] N. Rahman, M. Hoda-Nasrul, Validated spectrophotometric methods for the determination of amlodipine besylate in drug formulations using 2,3-dichloro-5,6-dicyano-1,4-benzoquinone and ascorbic acid. J. Pharm. Biomed. Anal. 31, 381 (2003).

[42] N. Rahman, D. Manisha Singh, M. Hoda-Nasrul, Application of oxidants to the spectrophotometric determination of amlodipine besylate in pharmaceutical formulations. IL Farmaco 59, 913 (2004).

[43] B. Kanakapura, C. Umakanthappa, N. Paregowda, Spectrophotometric and high performance liquid chromatographic determination of amlodipine besylate in pharmaceuticals. Scien. Asia 31, 13 (2005). 
[44] B. Kanakapura, C. Umakanthappa, N. Paregowda, Titrimetric and modified spectrophotometric methods for the determination of amlodipine besylate using bromate-bromide mixture and two dyes. Scien. Asia 32, 271 (2006).

[45] R. Sahu, V. B. Patel, Simultaneous spectrophotometric determination of amlodipine besylate and atorvastatin calcium in binary mixture. Indian J. Pharma. Scien.69, 110 (2007).

[46] H. M. Abdel-Wadood, N. A. Mohamed, A. M. Mahmoud, Validated spectrofluorometric methods for determination of amlodipine besylate in tablets. Spectro. Chim. Acta A70, 564 (2008).

[47] B. Hemmateenejad, R. Miri, R. Kamali, A kinetic spectrophotometric method for determination of amlodipine and nifedipie in pharmaceutical preparations. J. Iran. Chem. Soc.6, 113 (2009).

[48] H. H. Abdine, Spectrofluorimetric determination of amlodipine. Mansoura J. of Pharm. Scien.25, 31 (2009).

[49] S.B. Wankhede, K.C. Raka, S.B. Wadkar, S.S Chitlange, Spectrophotometric and HPLC methods for simultaneous estimation of amlodipine besilate, losartan potassium and hydrochlorothiazide in tablets. Indian Pharm. Scien.72, 136 (2010).

[50] M. S. Kondawar, K. G. Kamble, K. S. Raut, K. H. Maharshi, UV spectrophotometric estimation of amlodipine besylate and telmisartan in bulk drug and dosage form by multiwavelength analysis. Intern. J. Chem. Tech. Res.3, 1274 (2011).

[51] V. Vichare, V. Tambe, V. Kashikar, S. N. Dhole, Spectrophotometric simultaneous determination of amlodipine besylate and hydrochlorothiazide in combined tablet dosage form by simultaneous Equation, absorption ratio and first order derivative spectroscopy methods Inter. J. Chem. Res.2, 7 (2011).

[52] K. Schenker, J. Druey, helv. chim. acta42, 1960 (1970).

[53] R. E. Lyle, D. A. Nelson, J. Org. Chem.28, 169 (1963).

[54] P. J. Brignell, London (1964).

[55] J. Luis, Nu'nez-Vergara, R. Salazar, C. Camargo, J. Carbajo, B. Conde, P. Navarrete-Encinac, J. Squellaa, Oxidation of C4-hydroxyphenyl 1, 4-dihydropyridines in dimethylsulphoxide and its reactivity towards alkylperoxyl radicals in aqueous medium. Bioorganic and medicinal chemistry15, 4318 (2007).

[56] B. S. Furniss, A. J. Hannaford, P. W. G. Smith, A. R. Tatchell, Vogel's "Textbook of Practical Organic Chemistry". (Longman group UK Ltd, England, 1989).

[57] Oliner, Boyd, P. Job, Anal. Chem. "Advanced Physicochemical Experiments". (1964).

[58] D. M. Shingbal, S. R. Bhangle, Simple spectrophotometric analysis of nifedipine. IndianDrugs24, 490 (1987).

[59] D. C. Washington. (American Pharmaceutical Association, 2008), vol. I.

[60] $\mathrm{ICH}-\mathrm{Q} 2$ (R1) "International Conference on Harmonization of technical requirements for registration of pharmaceuticals for human use, text and methodology". (2005).

[61] IUPAC., Spectrochim. Acta, Part B.33 242 (1978).

[62] Raymond C. Paul J. Weller P. J. Rowe R. Shesky P. and weller P., "Handbook of Pharmaceutical Excipients", $4^{\text {th }}$ Edition.

[63] The British Pharmacopoeia, Majesty's stationary Office. (London, 2009), vol. I and II. 